\title{
Gastrointestinal Bleeding After Craniotomy: A Retrospective Review of 518 Patients
}

\author{
P. Muller, D. Jirsch, J. D’Sousa, C. Kerr and C. Knapp
}

\begin{abstract}
A retrospective review of the medical records of 518 patients who underwent craniotomy over a 3 year interval was carried out to determine the rate of gastrointestinal bleeding and its relationship to the Glasgow Coma Score. There were 288 [55.5\%] males and 230 [44.5\%] females in the series; the mean age was $51.5 \pm 18.9$ years. Forty percent had brain tumours, $18 \%$ had subarachnoid hemorrhage, $14 \%$ had spontaneous intracerebral hemorrhage, $19 \%$ had head injury and $8 \%$ had other diagnoses. Forty-eight [9.3\%] of the patients had significant gastrointestinal bleeding, the distribution of which was as follows: hematemesis [37/518], melena [11/518] and/or hematochezia [4/518]. A further 51 [9.8\%] had evidence of "coffee ground emesis" only. Of those with a Glasgow Coma Score of $<10,21 \%$ had significant GI bleeding while only $7 \%$ of patients with a Glasgow Coma Score $>10$ had such a bleed $[\mathrm{p}<0.005]$. Further analysis showed that the incidence of GI bleeding in patients who underwent craniotomy increased with decreasing GCS. GI bleeding did not correlate with age, sex, steroid administration or casual use of anti-ulcer medication.
\end{abstract}

RÉSUMÉ: Saignement gastro-intestinal post-crâniotomie - Etude rétrospective portant sur 518 patients Une étude rétrospective des dossiers médicaux de 518 patients ayant subi une crâniotomie au cours d'un intervalle de 3 ans a été entreprise afin de déterminer le taux de saignement gastro-intestinal chez ces patients et sa relation à l'échelle de coma de Glasgow. L'étude comprenait 288 hommes (55.5\%) et 230 femmes (44.5\%); l'âge moyen était de $51.5 \pm 18.9$ ans. Quarante pourcent avaient une tumeur cérébrale, $18 \%$ avaient une hémorragie sous-arachnoïdienne, $14 \%$ avaient une hémorragie intracérébrale spontanée, $19 \%$ avaient subi un traumatisme crânien et $8 \%$ avaient un autre diagnostic. Quarante-huit $(9.3 \%)$ patients ont présenté un saignement gastro-intestinal significatif dont la distribution se répartit comme suit: hématémèse (37/518), méléna (11/518) et/ou émission de selles sanguinolentes (4/518). Cinquante-et-un autres patients $(9.8 \%)$ avaient présenté seulement des vomissures avec apparence de café moulu. Parmi ceux qui avaient un score $<10$ à l'échelle de Glasgow, $21 \%$ ont présenté un saignement gastro-intestinal important alors que seulement $7 \%$ des patients qui avaient un score $>10$ à l'échelle de Glasgow ont présenté un tel saignement $\{\mathrm{p}<0.005\}$. Une analyse plus poussée a montré que l'incidence du saignement gastro-intestinal chez les patients qui ont subi une crâniotomie augmentait avec la chute du score à l'échelle de Glasgow. Le saignement gastro-intestinal n'était pas correlé avec l'âge, le sexe, l'administration de stéroides ou la prise occasionnelle d'une médication anti-ulcéreuse.

Can.J. Neurol. Sci. 1988; 15: 384-387

The problem of gastric erosion and upper gastrointestinal bleeding has been a well recognized complication in seriously ill neurosurgical patients since Harvey Cushing's original description. ${ }^{3}$ Cushing suggested that intracranial lesions may stimulate parasympathetic centres in the hypothalamus and the vagal nuclei at the floor of the 4th ventricle resulting in vagal over activity and subsequent gastric hyperacidity and hypermotility.

Although the mechanism of this "stress bleeding" is still uncertain, ${ }^{2}$ there is evidence that the erosive gastritis seen in neurosurgical cases is similar to that seen in other critically ill or injured patients. ${ }^{13}$ It has been noted by a number of authors that the incidence of "stress bleeding" has decreased significant- ly in the last several years; ${ }^{4}$ nevertheless, endoscopically identifiable gastric erosions are almost universal in severely injured patients ${ }^{2,14,1}$ and gastrointestinal bleeding is still a significant cause of morbidity. The incidence of gastrointestinal bleeding has been reported to be $6-20 \%$ of critically ill patients in an ICU setting. ${ }^{1}$ When massive gastrointestinal bleeding occurs the mortality rate is high. ${ }^{8}$

Factors which are considered to increase the chance of gastrointestinal bleeding secondary to stress ulceration include renal failure, sepsis, hypotension and major surgical procedure. 16,8 Post-mortem studies have shown a high incidence of upper gastrointestinal lesions in patients who died as the consequence of neurological disease when compared to other caus-

From the Divisions of Neurosurgery and General Surgery, Department of Surgery, St. Michael's Hospital, Toronto and Department of Surgery, University of Toronto, Toronto

Received September 15, 1987. Accepted in final form March 28, 1988

Reprint requests to: Dr. Paul Muller, St. Michael's Hospital, 38 Shuter St., Toronto, Ontario, Canada M5B 1A6 
es. ${ }^{12}$ In neurosurgical patients intracranial hypertension seems to be associated with a higher level of gastric acidity than is the case with normal ICP, although a correlation between ICP and gastric acidity has not been made. ${ }^{13}$

We have previously reported that gastrointestinal bleeding was significantly more common after craniotomy in patients with a Glasgow Coma Score equal to or $<10$ than it is in patients with a Glasgow Coma Score above $10 .{ }^{15}$ In the present study we have extended our previous observations by assessing 518 cases who had a craniotomy at St. Michael's Hospital in a three year interval, in order to determine the rate of gastrointestinal bleeding and in order to determine the relationship between the gastrointestinal bleed and the Glasgow Coma Score and other variables.

\section{METHODS}

The charts of 518 patients who underwent craniotomy at St. Michael's Hospital between 1981-1983 inclusive were reviewed.

For the purpose of our assessment significant gastrointestinal bleeding was defined as evidence of hematemesis, melena and/or hematochezia with or without "coffee ground" emesis. The identification of "coffee ground" alone was considered insufficient evidence of significant gastrointestinal bleeding.

The Glasgow Coma Scores [GCS] which were assessed were those at the time of admission, the worst preoperative score, the score at noon of the first post-operative day, the worst postoperative score and the score at discharge. The diagnostic categories included head injury, brain tumour, subarachnoid hemorrhage secondary to aneurysm, spontaneous intracerebral hemorrhage and other [which included craniotomy for microvascular decompression, craniotomy for brain biopsy, craniotomy for infection, craniotomy for skull defect and craniotomy for congenital malformation].

The significance of differences between groups was determined by the $\mathrm{X}^{2}$ statistic or the student $\mathrm{t}$-test. Multiple regression analysis was used to rank variables.

\section{RESULTS}

The mean age of the 518 patients was 51.5 [ \pm 18.9 s.d.] years. There were 288 [55.5\%] males and 230 [44.5\%] females in the series. Of the entire group $40 \%$ had brain tumours, $18 \%$ had subarachnoid hemorrhage, $14 \%$ had spontaneous intracerebral hemorrhage, $19 \%$ had head injury and $8 \%$ had other diagnoses. Forty-eight $[9.3 \%]$ had a significant gastrointestinal bleed [hematemesis $(37 / 518)$, melena (11/518) and/or hematochezia (4/518)]. A further 51 patients had "coffee ground" emesis only and were considered not to have had a significant gastrointestinal bleed.

The median time interval from admission to gastrointestinal bleed was 3 days. Twenty-six percent of those that bled did so on the day of admission, $35 \%$ did so within 2 days of admission and $70 \%$ bled in the first week. Fourteen bled pre-operatively, 27 on the day of surgery and 57 post-operatively.

Of those with a Glasgow Coma Score of $<10,21 \%$ had a significant gastrointestinal bleed, while only $7 \%$ of patients with a Glasgow Coma Score $>10$ had such a bleed $[p<0.005]$.

\begin{tabular}{ccc}
\hline Table 1: Relationship of Admission GCS to the GI Bleed Rate \\
\hline \hline $\begin{array}{c}\text { GCS } \\
\text { Category }\end{array}$ & $\begin{array}{c}\text { Number } \\
\text { of Cases }\end{array}$ & $\begin{array}{c}\text { Gastrointestinal } \\
\text { Bleed Rate }\end{array}$ \\
\hline $3-6$ & 71 & $21 \%$ \\
$7-10$ & 28 & $18 \%$ \\
$10-14$ & 90 & $16 \%$ \\
15 & 329 & $5 \%$ \\
\hline
\end{tabular}

\begin{tabular}{ccc}
\hline Table 2: Relationship of Post-Operative GCS to the GI Bleed Rate \\
\hline \hline $\begin{array}{c}\text { GCS } \\
\text { Category }\end{array}$ & $\begin{array}{c}\text { Number } \\
\text { of Cases }\end{array}$ & $\begin{array}{c}\text { Gastrointestinal } \\
\text { Bleed Rate }\end{array}$ \\
\hline $3-6$ & 59 & $27 \%$ \\
$7-10$ & 76 & $22 \%$ \\
$10-14$ & 122 & $10 \%$ \\
15 & 222 & $1 \%$ \\
\hline
\end{tabular}

Table 3: Relationship of Worst Post-Operative GCS to the GI Bleed Rate

\begin{tabular}{ccc}
\hline \hline $\begin{array}{c}\text { GCS } \\
\text { Category }\end{array}$ & $\begin{array}{c}\text { Number } \\
\text { of Cases }\end{array}$ & $\begin{array}{c}\text { Gastrointestinal } \\
\text { Bleed Rate }\end{array}$ \\
\hline $3-6$ & 119 & $23 \%$ \\
$7-10$ & 72 & $14 \%$ \\
$10-14$ & 194 & $5 \%$ \\
15 & 133 & $2 \%$ \\
\hline
\end{tabular}

Table 1 stratifies the admission Glasgow Coma Score into four categories according to the depth of coma; the lower the GCS the greater was the bleed rate. In Table 2 the 4 strata of the Glasgow Coma Scores recorded at noon of the first post-operative day are shown to correlate with the GI bleeding rate. And, in Table 3 the worst post-operative Glasgow Coma Score strata show a near linear relationship between the strata of the Glasgow Coma Score and the GI bleeding rate.

The mean Glasgow Coma Score for patients that bled was significantly lower than in those patients that did not bleed (Table 4).

Table 5 shows the relationship between diagnostic categories, admission Glasgow Coma Score and the GI bleed rate. Those diagnostic categories with the lowest Glasgow Coma Score are associated with the highest bleed rates. For example only $4 \%$ of patients with brain tumours had a gastrointestinal bleed and the mean admission GCS was $14.5 \pm 2.0$. On the other hand, $26 \%$ of patients with spontaneous intracerebral hemorrhage had gastrointestinal bleeding and the mean admission GCS was only $10.4 \pm 5.0$.

A total of 195 of the 518 patients received some form of prophylactic treatment [an $\mathrm{H} 2$ receptor antagonist or antacid]. The distribution of the use of prophylactic treatment among the categories of the Glasgow Coma Score appeared random. There were 20 patients who had a gastrointestinal bleed who received prophylactic treatment and 28 who had a bleed who did not receive prophylactic treatment. The prophylactic treatment did not entail gastric $\mathrm{pH}$ titration. There was no significant difference in the bleed rates in those who received and those who did not receive prophylactic treatment.

Sixty-nine percent [360/518] of patients received steroids, $9 \%$ of whom had GI bleeding; $11 \%$ of those that did not receive 
Table 4: Mean and S.D. Glasgow Coma Scores Stratified by GI Bleed

\begin{tabular}{lcc}
\hline \hline & $\begin{array}{l}\text { No GI } \\
\text { Bleed }\end{array}$ & GI Bleed \\
\hline Number of Patients & 469 & 49 \\
GCS: Admission & $13.4 \pm 3.5$ & $10.2 \pm 4.8^{\sim}$ \\
GCS: Worst pre-op & $13.0 \pm 3.6$ & $9.5 \pm 4.9^{\sim}$ \\
GCS: Noon 1st post-op day & $13.0 \pm 3.2$ & $8.9 \pm 3.8^{\sim}$ \\
GCS: Worst post-op & $11.7 \pm 4.1$ & $7.4 \pm 4.1^{\sim}$ \\
GCS: Discharge [3 if dead] & $13.1 \pm 4.2$ & $10.3 \pm 5.4^{\sim}$ \\
\hline
\end{tabular}

Table 5: Relationships Among Diagnostic Categories, Admission GCS and Bleeding Rates

\begin{tabular}{lccc}
\hline \hline Category & $\begin{array}{c}\text { Number } \\
\text { GCS } \pm \text { S.D. }\end{array}$ & $\begin{array}{c}\text { Admission } \\
{[\text { Type 2] }}\end{array}$ & Bleed Rate \\
\hline SICH & 73 & $10.4 \pm 5.0$ & $26 \%$ \\
Head Injury & 100 & $10.8 \pm 4.9$ & $8 \%$ \\
SAH & 94 & $13.3 \pm 3.4$ & $7 \%$ \\
Brain Tumour & 209 & $14.5 \pm 2.0$ & $4 \%$ \\
\hline
\end{tabular}

steroids had a GI bleed. This difference was not statistically significant $\left[X^{2}=0.6936\right]$.

Step wise regression analysis revealed that post-operative GCS had the highest predictive value for GI bleeding and that age, sex, use of steroids and prophylactic treatment had no effect.

\section{Discussion}

Gastrointestinal bleeding in critically ill patients occurs primarily from acute gastric erosion or acute hemorrhagic gastritis ["stress ulceration"] although some gastrointestinal bleeding may occur as the consequence of reactivation of a previous peptic ulcer. These stress ulcers or erosions appear in the corpus of the stomach and usually spare the antrum. They develop within hours of the stressful event and the incidence approaches 100\% when the insult is severe; the principle clinical manifestation is gastrointestinal bleeding. ${ }^{2}$ The incidence of identifiable gastrointestinal bleeding has been variously reported to be between 6 and $20 \%$ of critically ill patients treated in the ICU setting, depending on the severity of the patients' state and the nature of anti-ulcer treatment. ${ }^{1}$ For example, Priebe et al ${ }^{16}$ found gastrointestinal bleeding in $7 / 38$ [18\%] severely ill patients in ICU treated with cimetidine and Groll et al ${ }^{5}$ found an overall bleed rate of $8 \%$ in the ICU setting.

Factors which affect the development of stress ulceration include gastric acidity, mucosal secretory activity and mucosal blood flow. It is generally accepted that acid is required for ulcer formation and that ulcer formation is inversely related to the gastric $\mathrm{pH}$. The secretory activity of the mucosa plays an important role in protecting the mucosa from injury. Bicarbonate is produced in an amount equal to the acid secreted on the luminal side of the mucosa. Reduction in mucosal blood flow has been shown to be important in the pathogenesis of stress ulceration; however, it appears that the associated impairment of mucosal buffering capacity rather than mucosal ischemia is the important factor. ${ }^{16}$

Neutralization of gastric acidity by antacid treatment when the $\mathrm{pH}$ was titrated with the antacid was shown to reduce the incidence of gastrointestinal bleeding in severely ill patients. ${ }^{8}, 16$ Cimetidine may be ineffective in the treatment of stress ulceration since it impairs the secretory state of the mucosa, decreases intracellular buffering capacity and inadequately reduces the intraluminal acidity. 16

In a review of 2206 consecutive post-mortem examinations, $\operatorname{Karch}^{12}$ found hemorrhagic ulceration in the upper gastrointestinal tract in $7.2 \%$ of patients. The incidence of those dying of intracranial pathology was twice that of those dying of other causes. Upper gastrointestinal lesions were found at rates of $14.6 \%, 11.7 \%$ and $10.3 \%$ in patients with intracerebral hemorrhage, SAH and brain tumour, respectively. Although it is not possible to directly compare post-mortem lesions to clinical bleeding we found a bleed rate of $26 \%, 11 \%$ and $4 \%$ in cases of spontaneous intracerebral hemorrhage, subarachnoid hemorrhage and brain tumour, respectively. Although our proportions are different the relative incidence is similar to the post mortem series noted above.

Kamada et al ${ }^{10}$ in a review of 433 head injured patients divided them into three groups according to severity; the most severe were unconscious with abnormal motor responses [174 cases], the intermediate group were unconscious with normal motor responses [118 cases] and the least severe group were conscious [ 141 cases]. They defined gastrointestinal bleeding as hematemesis, melena, the presence of blood in aspirated gastric juice and bleeding at endoscopy. The bleed rates in these groups were $30 \%, 13 \%$ and $4 \%$, respectively. The overall bleed rate was $17 \%$. Of the 72 patients who bled, $39 \%$ did so within 48 hours of their head injury and $79 \%$ within a week. The time interval from admission to gastrointestinal bleeding in our postcraniotomy patients was very similar. Also, the bleeding rate by GCS was similar; we observed a bleeding rate of $24 \%$ for GCS $<11,10 \%$ for GCS of $11-14$ and $1 \%$ for GCS of 15 .

Gastroscopic studies have shown the incidence of visible gastric erosions or stress ulcers to be very much higher than the bleed rate. Larson et al ${ }^{13}$ fashioned gastroscopic assessment in 22 of 36 severely head injured patients and found gastric erosions in all 22; this occurred in spite of maintaining the gastric $\mathrm{pH}$ at levels greater than 4.5 . Other investigators have found gastric lesions in head injured patients at rates of $64 \%$ to $75 \% .^{7,11}$ In a study of 19 patients with severe head injury Gudeman et al 6 found evidence of gastrointestinal bleeding in 15 [79\%]; in 7 cases [37\%] more than two units of blood were required; 3 cases required surgical treatment.

Watt and Clark ${ }^{17}$ observed hyperacidity in head injured patients and noted that the hyperacidity was more pronounced in their decerebrate patients. Idjadi et $\mathrm{al}^{9}$ found an increase in acid and pepsin concentrations in patients with head injury when compared with normal controls. Larson et al ${ }^{13}$ found gastric acid levels higher in those with increased ICP compared with patients with normal ICP; however, in those with increased ICP the gastric acid and gastrin levels did not correlate with the ICP. ICP did correlate with pancreatic polypeptide. These investigators did find that head injured patients did not secrete more gastric acid than other seriously injured or ill patients.

Our series confirms the relationship between the probability of upper gastrointestinal hemorrhage and level of consciousness; the rate of upper gastrointestinal bleeding had a clear relationship to the Glasgow coma score. We also found that the use 
of steroids did not alter the bleed rate, nor did the use of "casual" anti-ulcer prophylaxis. We also demonstrated that gastrointestinal bleeding, if it develops, does so relatively early in the course of the patient's neurological illness. Although fatal gastrointestinal bleeding in seriously ill patients is becoming less frequent in the ICU setting, its occurrence continues to be a source of potential morbidity.

\section{ACKNOWLEDGEMENTS}

The authors wish to acknowledge the support of D. G. Searle and Co. of Canada Ltd. and to thank Ms. D. Evans for her editorial assistance.

\section{REFERENCES}

1. Bank S. Stress ulcers - prevention of gastrointestinal bleeding in critical care units. Med J Australia 1985; 142: 517-521.

2. Cheng LY. Treatment of established stress ulcer disease. World J Surg 1981; 5: 235-40.

3. Cushing H. Peptic ulcers and the interbrain. Surg Gynecol Obstet 1932; 55: 1-34.

4. Greenberg AG, Saik RP, Bell RH. Changing patterns of Gastrointestinal bleeding. Arch Surg 1985; 120: 341-344.

5. Groll A, Simon JB, Wigle RD, et al: Cimetidine prophylaxis for gastrointestinal bleeding in an intensive care unit. Gut 1986; 27 : 135-140.

6. Gudeman SK, Wheeler CB, Miller JD, et al. Gastric secretory and mucosal injury response to severe head trauma. Neurosurgery 1983; 12: 175-179.

7. Halloran LG, Zfass AM, Gayle WE, et al. Prevention of acute gastrointestinal complications after severe head injury: a controlled study of cimetidine prophylaxis. Am J Surg 1980; 39: 44-48.

8. Hastings PR, Skillman JJ, Bushnell LS, et al. Antacid titration in the prevention of acute gastrointestinal bleeding: a controlled. randomized trial in 100 critically ill patients. $\mathrm{N}$ Engl $\mathrm{J}$ Med 1978; 298: 1041-1045.

9. Idjadi F, Robbins R, Stahl WM, et al. Prospective study of gastric secretion in stressed patients with intracranial injury. $J$ Trauma 1971; 11: 681-688.

10. Kamada T, Fusamoto H, Kawano S, et al. Gastrointestinal bleeding following head injury: a clinical study of 433 cases. J Trauma 1977; 17: 44-47.

11. Kamada T, Fusamoto H, Kawano S, et al. Acute gastrointestinal lesions in head injury. Amer J Gastroenterol 1977; 68: 249-253.

12. Karch SB. Upper gastrointestinal bleeding as a complication of intracranial disease. J Neurosurg 1977; 37: 27-29.

13. Larson MG, Koch S, O'Dorisio TM, et al. Gastric response to severe head injury. Amer J Surg 1984; 147: 97-105.

14. Menguy R. The prophylaxis of stress ulceration. N Engl J Med 1980; 302: 461-462.

15. Muller PJ, Jirsch D, Knapp C, et al. The incidence and distribution of stress GI bleeding in neurosurgical patients. Canad J Neurol Sci 1985; 12: 194. [abst.]

16. Priebe HJ, Skillman JJ, Bushnell LS, et al. Antacid versus cimetidine in preventing acute gastrointestinal bleeding: A randomized trial in 75 critically ill patients. N Engl J Med 1980; 302: 426430.

17. Watt CC, Clark K. Gastric acidity in the comatose patient. J Neurosurg 1969; 30: 107-109. 